\title{
Konsep Religious Affections Jonathan Edward dalam konteks Pelayanan Pastoral Kaum Muda Gereja Injili
}

\author{
Jonathan Prasetia1
}

Penc dengan pelayanan kaum muda. Mark DeVries, seorang youth pastor, berkata, We are sending our kids into adulthood ill prepared for the increasing demands od our complex society. ${ }^{2}$ Individu yang menginjak usia remaja-pemuda sedang mengalami pencarian akan identitas diri dan mempertanyakan Tuhan, sehingga mereka mengalami gejolak emosional, kognitif, dan spiritual. ${ }^{3}$ Oleh sebab itu, apabila ibadah terasa kering, mereka akan cepat merasa bosan dan mencari gereja lain, di mana kebutuhan pengalaman akan Tuhan dapat dipenuhi. Dengan demikian pelayanan pastoral kaum muda sangat membutuhkan konsep kerohanian yang sesuai dengan gejolak jiwanya. Ketika kaum muda tidak mendapatkan kerohanian yang tepat sasaran dan pengalaman rohani yang nyata, maka kemungkinan besar mereka akan meninggalkan gereja.

Sebenarnya ada banyak warisan spiritualitas dari bapa-bapa gereja, namun tidak semuanya tepat sasaran bagi pendekatan pastoral kaum muda. Jonathan Edwards merupakan seorang gembala, pengkhotbah, teolog terbesar sepanjang sejarah yang memiliki fokus dengan pengalaman religius. Konsep Religious Affections yang tercetus dari lubuk hatinya merupakan salah satu konsep pengalaman religius yang alkitabiah. Berdasarkan teologinya, Edwards yang beraliran Calvinis, dikenal karena menyatukan semangat penginjilan dan keingintahuan intelektual dalam tulisan-tulisannya. ${ }^{4}$ Selain itu, afeksinya dalam berkhotbah selalu meninggikan Allah dan tidak pernah berhenti memuji Allah. ${ }^{5}$ Dalam diri Edwards, dapat dilihat keseluruhan pribadi, baik hati, jiwa, akal budi, dan kekuatan yang diserahkan kepada Allah. ${ }^{6}$ Ini membukti-

1. Alumnus STT SAAT Malang dan sekarang melayani sebagai youth pastor di GKY Green Ville.

2. Mark DeVries, Family Based Youth Ministry (Illinois: Intervarsity Press, 2004), 35.

3. Charles M. Shelton, Spiritualitas Kaum Muda (Jakarta: Kanisius, 1987), 66.

4. Wilfred J. Samuel, Kristen Kharismatik: Refleksi atas Berbagai Kecenderungan Pasca Kharismatik (Jakara: BPK Gunung Mulia, 2007), 15.

5. John Piper, Supremasi Allah dalam Khotbah (Surabaya: Momentum, 2008), 80.

6. Stephen J. Nicholls, Jonathan Edwards: Penuntun ke dalam Kehidupan dan Pemikirannya (Surabaya: Momentum, 2009), 6. 
Dalam khotbah tersebut, Edwards benar-benar menggambarkan murka Allah dengan perasaan yang begitu dramatis. Gambaran-gambaran atau analogi yang muncul menciptakan perasaan-perasaan yang sangat mendalam. Pada tahun 1742, kebangunan rohani tersebut perlahanlahan mulai menyebar ke wilayah-wilayah sekitarnya. Gereja-gereja yang tadinya dingin dan kering perlahan-lahan mulai diubahkan. ${ }^{10}$

Peristiwa yang sangat fenomenal itu ternyata menimbulkan persoalan baru bagi kekristenan saat itu. Ada kubu yang dinamakan "Enthusiasts"11 yang sangat menekankan pengalaman emosional dalam pencarian mereka akan Allah. Mereka mendapatkan pengalaman emosional yang tidak terkontrol dan kegembiraan yang meluap. ${ }^{12}$ Mereka sangat yakin pengalaman yang mereka dapatkan berasal dari Allah. Di sisi lain, ada kubu lain (golongan rasionalis) yang berpendapat bahwa kerohanian yang sejati adalah berpikir secara benar. Pengalaman religius tidaklah penting ketimbang doktrin atau pikiran. Kubu tersebut diwakili oleh pandangan Charles Chauncy yang mengkritik habis-habisan peristiwa Great Awakening. ${ }^{13}$ Menyikapi pergulatan kedua pandangan spiritualitas tersebut, Edwards membutuhkan waktu untuk memilah afeksi rohani yang sejati dari yang palsu. Edwards tidak setuju dengan kedua pandangan (ekstrem) tersebut. Dengan demikian lahirlah karyanya yang berjudul The Treatise Concerning Religious Affections yang diterbitkan tahun 1746 (dikhotbahkan tahun 1742), merupakan upayanya yang matang untuk mendeskripsikan tanda-tanda dari afeksi sejati. ${ }^{14}$

\section{Pengertian Afeksi dan Tanda-Tandanya}

Kunci dari pemikiran spiritualitas Jonathan Edwards terletak pada kata "afeksi." Edwards berpendapat bahwa "The affections are no other than the more vigorous and sensible exercises of the inclination and will of the soul."15 Penggunaaan kata afeksi sering disamakan dengan istilah lain, yaitu hati dan kehendak. Edwards berpendapat, “. . . it is sometimes called the 'inclination': and, as it has respect to the actions that are determined and governed by it, is called the "will": and the mind, with regard to the exercises of this faculty, is often called the 'heart'."16 Afeksi/hati adalah motivasi terkuat dari diri manusia, aspek yang

10. Ian H. Murray, Jonathan Edwards: A New Biography (Edinburgh: Banner of Truth,1987) ,166.

11. Golongan tersebut mengikuti ajaran “Enthusiasm." Berdasarkan arti katanya, "Enthusiasm” adalah being possessed by a God. Gerakan ini muncul sekitar abad 17. Ajarangerakan ini untuk mengecap inspirasi yang bersifat khayalan atau angan-angan. Pada abad 18, nama ini sudah tersebar luas untukmenunjuk pada devosi agama yang berlebihan. R. A. Knox, "Enthusiasm: A Chapter in the History of Religion," dalam The Oxford Dictionary of the Christian Church, ed. F. L. Cross (London: Oxford University Press, 1966) , 453.

12. John Piper, Gairah Allah bagi Kemuliaan-Nya (Surabaya: Momentum, 2008) ,98.

13. Roger Ward, "The Philosophical Structure of Jonathan Edwards's Religious Affections," Christian Scholar's Review 29/4 (Summer 2000) :745-768.

14. Piper, Gairah Allah bagi Kemuliaan-Nya, 99.

15. Jonathan Edwards, The Religious Affections (Carleslie: Banner of Truth and Trust, 2001) ,24.

16. Edwards, The Religious Affections, 24. 
paling men entukan segala sesuatu tentang siapa dia dan apa yang ia lakukan. ${ }^{17} \mathrm{Ed}-$ wards mengibaratkan afeksi bagaikan sebuah kemudi kapal yang mengendalikan kehidupan manusia. Dengan demikian afeksi/hati seharusnya menjadi fokus utama dalam spiritualitas Kristen. Tentu saja, afeksi yang dimaksud Edwards bukanlah afeksi biasa, melainkan afeksi yang kudus. ${ }^{18}$ Afeksi yang kudus akan memunculkan tanda-tanda afeksi yang sejati dan demikian juga sebaliknya.

Kedua belas tanda afeksi yang bukan merupakan afeksi sejati (tidak alkitabiah) terdiri dari: 19

(1) Semangat atau kehangatan religius yang berlebihan; (2) Pengaruh pada tubuh (manifestasi fisik); (3) Berbicara tentang agama; (4) Sumber selain diri sendiri; (5) Kemampuan untuk menghafal Alkitab; (6) Kasih yang tampak; (7) Beran eka ragam afeksi; (8) Afeksi yang mengikuti suatu pola; (9) Memberikan banyak sekali waktu untuk agama dan bersemangat dalam beribadah; (10) Memuji dan memuliakan Allah dengan berkata-kata; (11) Rasa percaya diri dalam pengalaman religius; (12) Tanda-tanda yang tampak di luar, yang bahkan meyakinkan orang-orang kudus.
Sedangkan tanda-tanda afeksi yang sejati (alkitabiah), diantaranya yaitu: ${ }^{20}$

(1) Sumber sejati: Afeksi sejati bersifat rohani, supernatural, dan Ilahi; (2) Menyenangi hal-hal rohani bukan demi kepentingan diri sendiri; (3) Mencintai hal-hal rohani karena keindahan dan keagungannya; (4) Iluminasi: pemahaman yang benar tentang hal-hal rohani; (5) Jaminan: keyakinan akan kenyataan dan kepastian hal-hal rohani; (6) Perendahan diri: suatu perasaan kurang dan tidak layak; (7) Transformasi: perubahan natur; (8) Keserupaan dengan Kristus: mengutamakan kasih, kelemahlembutan, ketenangan, pengampunan, belas kasih, keberanian, dan semangat rohani; (9) Kepekaan: hati yang lembut, bukan hati yang keras; (10) Keseimbangan dan proporsi: mencerminkan seluruh gambar Kristus, dan tidak berlebihan dalam afeksi; (11) Lapar rohani: lebih sedikit menyenangi diri sendiri dan hal-hal dosa tetapi menginginkan lebih banyak pertumbuhan rohani; (12) Menghasilkan buah: manifestasi iman sebagai pertanggungjawaban hidup.

17. Definisi afeksi dari Edwards menolak definisi dari kamus Webster yang mengartikan ka affection sebagai rasa sayang, kesetiaan a kasih kemudian affections yang diartikan sebagai emosi, perasaan, sentiment (wilayah emosi dari kasih). Afeksi yang dimaksud Edwards adalah sesuatu yang lebih kuat daripada definisi pertama dan lebih luas pengertiannya dari definisi kedua Gerald R. McDermott, Mengenal 12 Tanda Kerohanian Sejati (Yogyakar : Andi, 1995), 34.

18. McDermott, Mengenal 12 Tanda Kerohanian Sejati, 38.

19. Nicholls, Jonathan Edwards, 113.

20. Nicholls, Jonathan Edwards, 113

\section{YOulflf $_{\text {ministry }}$ Mei 2016}


Tanda-tanda afeksi yang dituliskan dalam bukunya, selalu disertai argumentasi berdasarkan ayat firman Tuhan. ${ }^{21}$ Konsep Religious Affections Jonathan Edwards memberikan porsiyang seimbang untuk spiritualitas Kristen. Ia menekankan pengalaman religius namun tetap bersandar pada pemahaman yang alkitabiah. Sam Storms menambahkan bahwa pemikiran Religious Affections Jonathan Edwards merupakan analisis spiritualitas yang akurat dan otentik dari pengalaman religius yang pernah ditulis. ${ }^{22}$ Pendekatan pastoral Jonathan Edwards yang cukup "berhati-hati" melihat afeksi seseorang (dalam keluar) ketimbang tanda-tanda yang dilihat secara fisik (permukaan luar saja) sangat dibutuhkan gereja-gereja masa kini secara khusus konteks pelayanan pastoral kaum muda.

\section{Kegalauan Kaum Muda dan Kece- masan Gereja Injili}

Ketika mengamati kondisi gerejagereja injili ${ }^{23}$ masa kini, McGrath mencetuskan kalimat yang sangat mengejutkan, "The perceived lack of credible, coherent and distinctive spirituality today. I do not in any way wish to alarmist or suggest that we are confronted with a crisis, a total lack of evangelical interest of spirituality."24 Kekurangan minat terhadap kerohanian seperti ini pasti berdampak pada kehidupan rohani kaum mudanya. Implikasinya, keyakinan dasar, metode berteologi, pertumbuhan rohani, disiplin rohani, atau segala hal yang berkaitan erat dengan spiritualitas, akan dinilai berdasarkan intelektual (pengetahuan) seseorang. Jikalau disiplin spiritual selalu dikaitkan dengan berdoa, meditasi, berkontemplasi, maka tidak demikian dengan spiritualitas Kristen injili. Mereka berpandangan sebaliknya, disiplin-disiplin semacam itu bukan persoalan yang penting dan tidak mungkin dilakukan. ${ }^{25}$

Kondisi demikian membuat spiritualitas injili kurang menaruh perhatian pada pengalaman religius. Itu sebabnya, banyak gereja-gereja injili saat ini sedang dilanda kekeringan rohani, sehingga menjadi gereja yang dingin, termasuk kaum muda dalam gerejanya. McGrath berpendapat, "The enlightenment forced evangelicalism into adopting approaches to spirituality which have resulted in rather cool, detached, and rational approaches to Scripture."26

21. Misalnya, dalam Perjanjian Lama dicat bagaimana kemurahan Allah kepada orang Israel benar-benar menggugah afeksi mereka sehingga mereka pun menaikkan puji-pujian bagi-Nya (Kel. 15:1-21). Namun, mereka segera juga melupakan karya-Nya. Kemudian, firman yang disampaikan Tuhan dengan peran bersungguh-sungguh dan berikrar, "Segala yang difirmankan Tuhan akan kami lakukan" (Kel. 19:8). Tetapi, tidak lama sesudah itu mereka pun menyembah patung anak lembu emas. Jonathan Edwards, Pengalaman Rohani Sejati (Surabaya: Momentum, 2008), 29.

22. Sam Storms, Signs of the Spirit: An Interpretation of Jonathan Edwards Religious Affections (Wheaton: Crossway, 2007$), 21$.

23. Pertama-tama istilah "Injili" muncul ketika beberapa tahun setelah reformasi, pada tahun 1529. Erasmus yang sangat setia pada Paus menulis tentang orang-orang Protestan dan menyebutkan, "some who falsely boast they are Evangelicals" (lih. Yakub B. Susabda, Kaum Injili: Membangkitkan Kembali Iman Kristiani Ortodoks [Malang: Gandum Mas, 1991], 15). Jelas terlihat bahwa istilah "Injili" awalnya digunakan untuk golongan Protestan, sekaligus membedakan (secara pengajaran) dari Roma Katolik (bdk. Paulus Daun, Apakah Evangelikalisme itu? [Manado: Yayasan Daun Family, 2006], 12).

24. Alister E. McGrath, Evangelicalism and the Future of Christianity (Downers Grove: InterVarsity, 1995$), 122$.

25. McGrath, Evangelicalism and the Future of Christianity, 167.

26. Alister E. McGrath, A Passion for Truth: The Intellectual Coherence of Evangelicalism (Downers Grove: Intervarsity, 1998), 175. 
Dampaknya, kaum muda merasakan kejenuhan yang luar biasa ketika beribadah dalam gereja-gereja injili. Sebenarnya mereka sangat haus, lantas tidak mendapatkan pemuasan secara spiritual. Kaum muda yang seharusnya menjadi generasi penerus gereja akan mengalami kemandegan dalam pertumbuhan rohaninya. Oleh sebab itu, sebagian besar kaum muda dari gereja-gereja injili dan gerejagereja tradisional beralih ke gereja karismatik yang dibanjiri oleh pengalaman religius.

Spiritualitas karismatik memiliki keunikan, yaitu sangat mementingkan pengalaman religius. Tidak hanya melibatkan perasaan religius atau sukacita serta pergumulan hidup, tetapi pengalaman secara personal antara manusia dengan Allah. ${ }^{27}$ Ibadah akan diiringi dengan pengalamanpengalaman seperti menangis, menjerit, rebah, bergulingan, menari-nari, berjatuhan, mabuk, dan mengaum-ngaum seperti singa. Karunia yang paling utama dan paling banyak dibicarakan adalah glossolalia (bahasa lidah), nubuat, dan penyembuhan. ${ }^{28}$ Kuasa rohani secara nyata terwujud dalam kemampuan memuji Allah, menginjili, mengusir setan, mempraktikkan karunia-karunia Roh dalam pemberitaan Firman, serta pelayanan sakramen, disertai dengan sukacita, kegembiraan dan pengalaman religius yang sangat nyata. ${ }^{29}$

Tanda-tanda rohani yang dirasakan nyata seperti inilah yang menyihir kaum muda gereja injili yang merasakan kekosongan kemudian beralih pada spiritualitas karismatik. Kaum muda yang memiliki emosi cenderung labil akan langsung mendapatkan pemuasan rohani. Figurfigur ${ }^{30}$ pendeta muda yang sangat berkarisma dalam berkhotbah, akan semakin memikat hati mereka. Ditambah dengan faktor pertemanan dan persahabatan yang hangat dan akrab semakin mempererat mereka di dalam komunitas.

Sejujurnya hal ini tidak menyelesaikan persoalan. Ibarat orang yang senang menggali lubang dan menutup lubang. Ada bahaya baru ketika mereka tinggal dalam gereja karismatik. Mereka cenderung menggunakan emosi sebagai acuan dalam spiritualitasnya lalu mengabaikan akal budi yang Tuhan ciptakan. Jikalau mereka mengalami kekecewaan kembali, kemungkinan besar mereka tidak pergi ke gereja (termasuk juga enggan beribadah di gereja karismatik), dan bahkan menjual imannya. Hal ini disebabkan karena pengalaman rohani yang mereka miliki tidak disertai dengan pemahaman yang alkitabiah. ${ }^{31}$

27. R. P. Spittler, "Spirituality, Pentacostal and Charismatic," dalam Dictionary of Pentecostal and Charismatic Movements, ed. Stanley M. Burgess dan Gary B. McGee (Grand Rapids: Zondervan, 1989), 804.

28. Jan S. Aritonang, Berbagai Aliran di dalam dan di Sekitar Gereja (Jakarta: Gunung Mulia, 1999), 219.

29. Kenneth E. Hagin, Bagaimana Anda Dituntun oleh Roh Allah (Jakarta: Immanuel, 1990), 179-180.

30. Berbagai media informasi menciptakan citra diri sebagai bagian kehidupan remaja kelas a ini yang menginformasikan berbagai cara bergaul maupun perlengkapan hobi yang relevan bagi remaja. Cerita para idola remaja yang mendominasi dunia hiburan yang gaya hidupnya sering mereka tiru. John W. Santrock, Adolescence Perkembangan Remaja (Jakarta: Penerbit Erlangga, 1996), 187.

31. David Kinnaman, You Lost Me (Bandung: VisiPress, 2012), 23.

\section{Youlflf | Mei 2016}


Konsep Religious Affections Jonathan Edwards dalam Konteks Pelayanan Pastoral Kaum Muda

Pelayanan pastoral adalah istilah yang sangat luas untuk memayungi semua pelayanan gerejawi yang bersifat pastoral. ${ }^{32}$ Termasuk di dalamnya kepemimpinan, ibadah, konseling, kunjungan, administrasi, berkhotbah dan mengajar. Penulis membatasi pelayanan pastoral kaum muda yang dimaksud dalam pembahasan ini adalah pelayanan pendampingan atau pastoral care kepada kaum muda.

Pendampingan pastoral (pastoral care) adalah sebuah aksi sadar yang melampaui kecenderungan naluriah kita sebagai manusia. Allah yang Maha Kasih senantiasa mendampingi sebagai pribadi dan anggota komunitas beriman, oleh karena itu, sudah layak dan sepantasnyalah kalau kita saling mendampingi. ${ }^{33}$ Adapun bermacam-macam fungsinya, ${ }^{34}$ namun sederhananya adalah tujuan dari pelayanan pendampingan kaum muda ini untuk mendemonstrasikan kehadiran dan kasih Allah agar hidup rohani kaum muda mengalami keserupaan dengan Kristus. Apabila dikaitkan dengan konsep Religious Affections, maka dalam upaya pendampingan terhadap kaum muda kita harus selalu melihat afeksi di balik tanda-

\section{Pendampingan pastoral [pastoral care] adalah sebuah aksi sadar yang melampaui kecenderungan naluriah kita sebagai manusia. Allah yang Maha Kasih senantiasa mendampingi sebagai pribadi dan anggota komunitas beriman, oleh karena itu, sudah layak dan sepantasnyalah kalau kita saling mendampingi.}

tanda rohani yang nampak dalam perilaku rohani mereka.

Dalam hal disiplin rohani (ibadah, membaca firman Tuhan, berdoa, kelompok kecil, dan pelayanan), kita dapat mengamati tanda-tanda yang nampak dalam perilaku rohani kaum muda, lalu membandingkannya dengan dua belas tanda afeksi yang sejati dan tidak sejati. Intinya ketika kita melihat tanda-tanda yang nampak, kita harus dapat melihat esensi yang paling penting, yaitu afeksi. Misalnya, sesuai dengan afeksi sejati sebagai tanda pertama: Sumber afeksi sejati bersifat rohani, supernatural, dan Ilahi. Kita dapat memunculkan pertanyaan kri-

32. Daniel Susanto, Sekilas tentang Pelayanan Pastoral di Indonesia (Jakara: GKI Menteng, 2010), 25.

33. Hendri Wijayatsih, "Pendampingan dan Konseling Pastoral" http://ukdw.ac.id/journal-theo/index.php/gema/article/viewFile/ 122/pdf (diakses 28 September 2017).

34. Empat fungsi penggembalaan di sepanjang abad, (1) Menyembuhkan. Dalam fungsi ini bukan hanya fisik namun menolong mereka yang mengalami luka batin (2) Menguatkan. Bagian ini berfungsi untuk memberikan pengharapan di dalam Tuhan (3) Membimbing. Bagian ini berfungsi untuk menolong dalam pengambilan keputusan (4) Memulihkan. Bagian ini berfungsi untuk mengembalikan relasi yang sehat antara sesama dan Tuhan. (Tambahan penulis: keempat fungsi yang sudah berjalan sepanjang abad ini juga seharusnya dapat diterapkan pada kaum muda Kristen). Howard Clinebell, Tipe-Tipe Dasar Pendampingan dan Konseling Pastoral (Yogyakarta: Kanisius, 2002), 55. 
tis sambil mengamati mereka, faktor apa yang menggerakkan mereka? Apakah kegiatan yang mereka kerjakan digerakkan oleh faktor dari dalam atau dari luar? Untuk apa mereka melakukan disiplin rohani tersebut? Apakah kaum muda melakukan disiplin rohani karena Roh Kudus berdiam di dalam hati mereka? Apakah mereka menjalankan disiplin rohani tersebut dengan berelasi secara personal dengan Tuhan?

Demikian juga ketika kita sedang mendampingi anak muda yang menghadapi tekanan hidup yang berat, maka peran kita bukan hanya menolong mereka agar mereka berhasil melewati pergumulan tersebut. Dalam tanda afeksi yang sejati, dapat kita lihat tanda yang ke-7 yakni transformasi serta perubahan natur; dan tanda ke-8 yakni keserupaan dengan Kristus: mengutamakan kasih, kelemahlembutan, ketenangan, pengampunan, belas kasih, keberanian, dan semangat rohani. Kita dapat mengarahkan kaum muda untuk melihat apa yang Tuhan kerjakan dalam hidup mereka ketika menghadapi kesulitan tersebut? Apakah ada perubahan hidup yang Tuhan sedang kerjakan dalam diri mereka? Apakah mereka menghadapi pergumulan tersebut dengan ketenangan dan keberanian? Apakah masih ada kasih dan pengampunan dalam hidup rohani mereka? Seharusnya dalam percakapan pastoral, tanda afeksi yang sejati dapat terlihat ketika kaum muda yang bergumul mengeluarkan kata-kata seperti si Pemazmur, Sebab Engkau telah menguji kami, ya Allah, telah memurnikan kami, seperti orang memurnikan perak (Mzm. 66:10).

Pada akhirnya, ketika kita menerapkan konsep Religious Affections Jonathan Edwards dalam pelayanan pastoral care pada kaum muda, akan memunculkan tanda ke-12, yaitu menghasilkan buah: manifestasi iman sebagai pertanggungjawaban hidup. Artinya, kaum muda yang memiliki iman di dalam Dia, pasti akan berdampak dalam kehidupan praktisnya. Sejalan dengan Yakobus 2:16, sebab seperti tubuh tanpa roh adalah mati, demikian jugalah iman tanpa perbuatan-perbuatan adalah mati. Sudah semestinya mewujudkan pelayanan pastoral kaum muda yang memfokuskan pada afeksi membutuhkan waktu, tenaga, dan proses yang panjang. Kita tidak mungkin dapat mengerjakan seorang diri. Kita harus melibatkan orang lain yang dewasa rohani sebagai mentor (yang sebelumnya dilatih dan dibekali terlebih dahulu) dan menyediakan kelompok-kelompok kecili ${ }^{35}$ yang dilakukan secara intensional agar setiap pendamping dapat lebih efektif memperhatikan kerohanian kaum muda dengan jumlah yang lebih sedikit.

35. Kelompok kecil adalah komunitas yang transformasional yang belajar memahami Alkitab, berdoa dan bersama-sama berpartisipasi dalam misi Allah bagi tujuan-tujuan pekerjaan Allah yang mengubahkan. J. Alex Kirk, Komunitas yang Diubahkan (Jakarta: Perkantas, 2010), 17.

\section{Youlfll}


Tantangan bagi Gereja-Gereja Injili dalam Mengembangkan Pelayanan Kaum Muda

\section{Bagi Para Pembina Rohani Kaum Muda}

Berkaca dari konsep Religious Affections Jonathan Edwards, maka dapat disimpulkan bahwa yang terpenting adalah hati atau afeksi sebagai pusat kendali hidup manusia. Hal ini menunjukkan bahwa dalam pelayanan kaum muda harus mengedepankan pastoral care atau pembimbingan bagi kaum muda. Tujuannya, ketika pembina melihat tanda-tanda afeksi yang muncul dari kaum muda yang mereka layani, apakah tanda yang muncul bersifat sejati atau tidak sejati? Apakah kaum muda yang dilayani sudah memiliki keseimbangan dalam spiritualitasnya? Namun sayangnya, dewasa ini sebagian besar pembina kaum muda gereja injili sangat sibuk dengan berbagai program dan kegiatan, sehingga tidak waktu untuk melihat afeksi anak-anak muda yang mereka layani. Kepuasan muncul ketika jumlah jemaat yang hadir lebih banyak dari ibadah sebelumnya, tanpa memikirkan bagaimana pertumbuhan kerohanian mereka. Para pembina dan pembimbing kaum muda sibuk memikirkan event-event kebersamaan anak muda, ketimbang mengupgrade skill untuk menggembalakan kaum muda.

Demikian juga dalam hal berkhotbah. Dalam ibadah kaum muda, gereja injili sangat mengutamakan faktor pengkhotbah dan pemberitaan firman Tuhan. Hal berkhotbah juga merupakan salah satu bagian dalam pelayanan pastoral Oleh karena itu, khotbah seharusnyayang diberitakan bukan hanya mengisi pengetahuan tentang Allah, tetapi juga mengikutsertakan afeksi di dalamnya. John Piper yang ikut menambahkan:

Jika berkhotbah seharusnya bertujuan untuk membesarkan Allah, dan jika Allah dibesarkan ketika umat-Nya lebih menyukai Dia ketimbang segala "kekayaan dan kenikmatan hidup" (Luk. 8:14), maka khotbah harus bertujuan untuk mengekspos kesenangan-kesenangan dosa yang merupakan tindakan bunuh diri, dan membangunkan kepenuhan sukacita di dalam Allah... Afeksi yang tertinggi berakar di dalam, dan disesuaikan oleh, kebenaran - itulah sasaran dari khotbah. Kebenaran adalah kemuliaan yang beragam dari Allah dalam firmanNya; dan afeksi yang tinggi adalah kesukaan karena mengenal Allah dan ketakutan jika tidak berbahagia di dalam Dia. ${ }^{36}$

\section{Bagi Para Pemimpin dan Sinode Gereja}

Untuk memaksimalkan pelayanan pastoral care kaum muda, maka peran dan jabatan youth pastor dalam sebuah gereja lokal sangat urgent dibutuhkan. Astri Sinaga, dosen STT Amanat Agung, menambahkan bahwa gereja tidak benar-benar memikirkan mengapa perlu merekrut seorang hamba Tuhan khusus menangani kaum muda. ${ }^{37}$

"Responden yang melihat bahwa tantangan terbesar adalah dirinya sendiri, ketika ditanyai lebih lanjut, mengungkap-

36. Piper, Gairah Allah bagi Kemuliaan-Nya, 29.

37. Astri Sinaga, “Pelayan Kaum Muda dalam Tantangan dan Kesulitan," Jurnal Youth Ministry 2 (Mei 2014): 10-11. 
kan bahwa mereka sendiri sebenarnya tidak punya panggilan yang khusus di dalam pelayanan kaum muda. Mereka melayani kaum muda lebih karena gereja menempatkan gereja di sana, padahal sesungguhnya pelayanan kaum muda bukanlah minat mereka yang paling utama. Inilah alasan yang menyebabkan tidak ada perjuangan dan pengorbanan ketika melihat adanya keterbatasan waktu. Nampaknya gereja pun tidak terlalu memperhatikan apakah seseorang memiliki gairah dan minat dalam pelayanan kaum muda sehingga dia ditempatkan di pelayanan itu. Gereja mengangkat dan menempatkan seseorang untuk melayani di kaum muda, tetapi sesungguhnya gereja sendiri tidak memiliki visi atau tujuan secara khusus tentang mengapa mereka perlu merekrut seorang hamba Tuhan untuk kaum muda."
Dalam hal ini, pihak Sinode perlu duduk bersama dengan gereja lokal memikirkan dan menyediakan jabatan youth pastor dan setidaknya menempatkan satu orang youth pastor dalam satu gereja lokal tersebut dalam jangka waktu yang panjang. ${ }^{38}$ Jikalau masing-masing gereja-gereja injili setidaknya memiliki satu youth pastor (arti: diprioritaskan serta tidak mengurusi bidang lain atau memegang jabatan lain), maka ia dapat efektif menggunakan seluruh waktu, tenaga, dan pikirannya. Ia dapat menggali kembali mengenai spiritualitas yang tepat dan memikirkan strategi pelayanan pastoral yang efektif bagi kaum muda. Dengan demikian kaum muda gereja injili akan mengalami pertumbuhan rohani secara signifikan.

38. Penulis mengamati kondisi gereja-gereja injili. Setelah pembina kaum muda dalam sebuah gereja injili telah sukses melayani kaum muda, biasanya ia segera dipindahkan untuk melayani bidang yang lain, yang berkaiman dengan orang dewasa. Demikian juga penulis mendapati jurnal yang sangat minim berkaitan dengan pelayanan kaum muda, dan juga budget yang minim untuk pengembangan pelayanan kaum muda. Hasil obeservasi ini, penulis ingin membuktikan bahwa sedikit gereja injili yang sungguh-sungguh menggarap pelayanan kaum mudanya.

\section{Youlfh | Mei 2016}




\section{Daftar Pustaka}

\section{Buku}

Aritonang, Jan S. Berbagai Aliran di dalam dan di Sekitar Gereja. Jakarta: Gunung Mulia, 1999.

Clinebell, Howard. Tipe-Tipe Dasar Pendampingan dan Konseling Pastoral. Yogyakarta: Kanisius, 2002.

Daun, Paulus. Apakah Evangelikalisme itu? Manado: Yayasan Daun Family, 2006.

DeVries, Mark. Family Based Youth Ministry. Illinois: Intervarsity Press, 2004.

Edwards, Jonathan. God at Work. Surabaya: Momentum, 2004. . Pengalaman Rohani Sejati. Surabaya: Momentum, 2008. . The Religious Affections. Carleslie: Banner of Truth and Trust, 2001.

Hagin, Kenneth E. Aku Percaya akan Penglihatan. Jakarta: Immanuel, 1991. Bagaimana Anda Dituntun oleh Roh Allah. Jakarta: Immanuel, 1990.

Kinnaman, David. You Lost Me. Bandung: VisiPress, 2012.

Kirk, J. Alex. Komunitas yang Diubahkan. Jakarta: Perkantas, 2010.

Knox, R. A. "Enthusiasm: A Chapter in the History of Religion." Dalam The Oxford Dictionary of the Christian Church, diedit oleh F. L. Cross. London: Oxford University Press, 1966.

McDermott, Gerald R. Mengenal 12 Tanda Kerohanian Sejati. Yogyakarta: Andi, 1995.

McGrath, Alister E. A Passion for Truth: The Intellectual Coherence of Evangelicalism. Downers Grove: Intervarsity, 1998.

. Evangelicalism and the Future of Christianity. Downers Grove: InterVarsity, 1995. 
Murray, Ian H. Jonathan Edwards: A New Biography. Edinburgh: Banner of Truth, 1987.

Nicholls, Stephen J. Jonathan Edwards: Penuntun ke dalam Kehidupan dan Pemikirannya. Surabaya: Momentum, 2009.

Piper, John. Gairah Allah bagi Kemuliaan-Nya. Surabaya: Momentum, 2008. . Supremasi Allah dalam Khotbah. Surabaya: Momentum, 2008.

Samuel, Wilfred J. Kristen Kharismatik: Refleksi atas Berbagai Kecenderungan Pasca Kharismatik. Jakarta: BPK Gunung Mulia, 2007.

Santrock, John W. Adolescence Perkembangan Remaja. Jakarta: Penerbit Erlangga, 1996.

Shelton, Charles M. Spiritualitas Kaum Muda. Jakarta: Kanisius, 1987.

Spittler, R. P. "Spirituality, Pentacostal and Charismatic." Dalam Dictionary of Pentecostal and Charismatic Movements, diedit oleh Stanley M. Burgess dan Gary B. McGee. Grand Rapids: Zondervan, 1989.

Storms, Sam. Signs of the Spirit: An Interpretation of Jonathan Edwards Religious Affections. Wheaton: Crossway, 2007.

Susabda, Yakub B. Kaum Injili: Membangkitkan Kembali Iman Kristiani Ortodoks. Malang: Gandum Mas, 1991.

Susanto, Daniel. Sekilas tentang Pelayanan Pastoral di Indonesia. Jakarta: GKI Menteng, 2010.

\section{Jurnal}

Sinaga, Astri “Pelayan Kaum Muda dalam Tantangan dan Kesulitan," Jurnal Youth Ministry 2 (Mei 2014): 10-11.

Ward, Roger. "The Philosophical Structure of Jonathan Edwards's Religious Affections," Christian Scholar's Review 29/4 (Summer 2000): 745-768. 


\section{Internet}

Purwanto, Eddy Peter. "Siapakah Kaum Puritan?" http://www.sttip.com/puritans\% 20introduction.htm (diakses 28 September 2010).

Wijayatsih, Hendri. “Pendampingan dan Konseling Pastoral” http://ukdw.ac.id/journaltheo/index.php/gema/article/viewFile/122/pdf (diakses 28 September 2017). 